\title{
Osteometrical and CT Examination of the Japanese Wolf Skull
}

\author{
Hideki ENDO, Iwao OBARA ${ }^{1)}$, Tomohiro YOSHIDA2), Masamichi KUROHMARU ${ }^{2)}$, Yoshihiro HAYASHI'), and \\ Naoki SUZUKI ${ }^{3)}$ \\ Departments of Zoology and ${ }^{1)}$ Education, National Science Museum, Shinjuku-ku, Tokyo 169, ${ }^{2}$ Department of Veterinary Anatomy, \\ Faculty of Agriculture, The University of Tokyo, Bunkyo-ku, Tokyo 113, and ${ }^{3}$ Department of Medical Engineering, The Jikei University \\ School of Medicine, Minato-ku, Tokyo 105, Japan
}

(Received 28 January 1997/Accepted 19 March 1997)

ABSTRACT. The skulls of Japanese wolf (Canis hodophilax) were osteometrically examined and compared with those of Akita-Inu. The skull total length was not statistically different between two species. However, significant differences were demonstrated between two species in some ratios concerning the frontal bone. CT examination was carried out in the Japanese wolf skull. The data indicated that the frontal sinus is not be largely developed and compressed in the dorso-ventral direction in parasagittal area. The narrow frontal sinus fitted to external shape of the frontal bone. The cribriform plate had a well-developed complicated structure in a caudal part of the ethmoid bone. These data will be useful to examine the respiratory function and the olfactory sense in the Japanese wolf. — KEY wORDS: Akita-Inu, CT, Japanese wolf, osteometry, skull.

The Japanese wolf (Canis hodophilax Temminck 1839) is one of the extinct species, that has not been recorded since 1905. It is a smaller wolf similar to the Akita breed (AkitaInu) of domesticated dog (Canis familiaris LinNAEus 1758) in some external morphological characters [1, 11, 12, 20, 23, 24]. Some osteological characters have also been examined in the two animals [1, 6, 11-14, 16-18]. However, the skull proportion of the Japanese wolf has not been compared with that of the dog. The frontal bone shape has been considered as a distinct factor of the Japanese wolf $[6,17,18]$. They pointed out that the frontal part is not developed in the Japanese wolf cranium in lateral and rostral aspects. So, it has been expected to compare some skull measurements of the Japanese wolf to those of the AkitaInu, and to confirm the specific osteological characters of frontal bone in each species. In the frontal area, the internal structure such as frontal sinus, cribriform plate, nasal cavity should be examined in size and shape. The CT and three dimensional CT reconstruction methods may be useful for this aim.

\section{MATERIALS AND METHODS}

Osteometrical study: We used all crania and skulls of the Japanese wolf stored in the Department of Zoology of the National Science Museum (Tokyo, Japan), whereas the male specimens larger than $200 \mathrm{~mm}$ in the total length were selected from the Akita-Inu collections of the Museum (Table 1). Recorded biological data of the specimens are arranged in Table 1. However, unrecorded data of sex were not estimated from two Japanese wolf specimens (M1185 and M26696) in this study. M 100 is a male specimen, so only male specimens were used in the Akita-Inu.

The skulls were measured for 28 items (Table 2). Most measurements were performed according to the methods of Driesch [2], while some other items were evaluated as described by Saito [21] (Table 2). Measurements were carried out with a vernier caliper to the nearest $0.1 \mathrm{~mm}$. Ratios to the TL were obtained for some measurements. The significant differences of TL values and some ratios between two species were determined by Student's $t$-test. The TL could not be measured in M1185, whereas the LCP could not be evaluated in M26696. So, LCP/BL were calculated to be compared with those of Akita-Inu.

CT examination: The skull of a Japanese wolf (M1185) was serially sectioned with the CT scanner in sagittal direction with $2 \mathrm{~mm}$ pitch in $2 \mathrm{~mm}$ thickness. The internal shape of frontal sinus was observed in these sections. Images were reconstructed from the data of serial sections of M1185. Three dimensional reconstructed image was cut

Table 1. Specimens used in this study

\begin{tabular}{|c|c|c|c|c|}
\hline \multicolumn{5}{|c|}{ 1. Japanese wolf } \\
\hline $\begin{array}{l}\text { Museum } \\
\text { Number }\end{array}$ & $\begin{array}{c}\text { Age } \\
\text { (month) }\end{array}$ & Sex & Locality & $\begin{array}{l}\text { Year of } \\
\text { capture }\end{array}$ \\
\hline M100 & $\mathrm{NE}$ & male & Fukushima Pre. & about 1870 \\
\hline M1185 & NE & $\mathrm{NE}$ & Fukui Pre. & about 1800 \\
\hline M26696 & $\mathrm{NE}$ & $\mathrm{NE}$ & Okutama district & NR \\
\hline \multicolumn{5}{|c|}{ 2. Dog (Akita-Inu) } \\
\hline $\begin{array}{l}\text { Museum } \\
\text { Number }\end{array}$ & $\begin{array}{c}\text { Age } \\
\text { (month) }\end{array}$ & Sex & & \\
\hline M3879 & $\mathrm{NE}$ & male & & \\
\hline M12921 & $\mathrm{NE}$ & male & & \\
\hline M18303 & 15 & male & & \\
\hline M12920a) & $\mathrm{NE}$ & male & & \\
\hline M19301 & 14 & male & & \\
\hline
\end{tabular}

All biological data have been recorded with specimens.

NE: neither recorded nor estimated.

NR: not recorded.

a) Crainum without mandible. 
Table 2. List of the measurements and their abbreviations ${ }^{\text {a) }}$

Total length (Akrokranion-Prosthion) -

$\begin{array}{ll}\text { Total length (Akrokranion-Prosthion) } & \text { TL } \\ \text { Basal length (Basion-Prosthion) } & \text { BL }\end{array}$

Condylobasal length CBL

Upper neurocranium length (Akrokranion-Frontal midpoint) UNL

Palatal length

Facial length (Frontal midpoint-Prosthion)

Distance between orbit and nasal end ${ }^{\text {b) }}$

Zygomatic breadth (Zygion-Zygion)

Greatest neurocranium breadth (Euryon-Eyryon) GNB

Greatest mastoid breadth (Otion-Otion) GMB

Frontal breadth (Ectorbitale-Ectorbitale) FB

Least breadth of skull LBS

Least breadth between the orbits (Entorbitale-Entorbitale) LBO

Greatest palatal breadth $\quad$ GPB

Height of the occipital triangle (Akrokranion-Basion) HOT

Total length (length form condyle process) LCP

Length from angular process to aboral border $\quad$ LAA of the canine alveolus

Height of the vertical ramus HVR

Length from $\mathrm{I}^{1}$ to $\mathrm{M}^{2 \mathrm{c})}$ LIM

Length of cheektooth row $\quad$ LCR

Length of upper canine ${ }^{\mathrm{d})}$ LUC

Breadth of upper canine ${ }^{\mathrm{e})} \quad$ BUC

Length of lower canine ${ }^{\text {f) }}$ LLC

Breadth of lower canine ${ }^{g)}$ BLC

Length of $\mathrm{P}^{4} \quad$ LP4

Breadth of $\mathrm{P}^{4} \quad$ BP4

Length of $\mathrm{M}^{1} \quad$ LUM

Length of $\mathrm{M}_{1} \quad$ LLM

a) The measurements without footnote were based on Driesch [2].

b) Synonym of Länge der Schnauze, vom Alveolarrand eines der mittleren Schneidzähne bis zum Vorderrand der Augenhöhle [21].

c) Synonym of Dentallänge von Incisivalveolen bis zum Mittelpunkt der Vorfindungslinie zwischen den hinteren Alveolarrändern des oberen letzten Höckerzahns [21].

d) Synonym of Grösste Länge des oberen Eckzahns am äusseren Grunde des Zahnalses [21].

e) Synonym of Breite des oberen Eckzahns [21]

f) Synonym of Grösste Länge des unteren Eckzahns am äusseren Grunde des Zahnhalses [21].

g) Synonym of Breite des unteren Eckzahns [21].

on the image in parasagittal plane. Then, the structure of frontal sinus, cribriform plate, nasal cavity, and inner shape of the frontal bone, nasal bone and maxilla were observed in these sections.

\section{RESULTS}

The cranium and mandible of the Japanese wolf and Akita-Inu are shown in Figs. 1-6. A gentle curve line was observed in the frontal part in the lateral aspects in the Japanese wolf, whereas the dorsal outline rose immediately as a stop in this portion of the Akita-Inu (Figs. 1, 2). The frontal bone was more developed laterally in the Akita-Inu than in the Japanese wolf (Figs. 3, 4). The value of measurements in the skulls are given in Table 3 . The interspecies statistical difference was not shown in TL. Some measurement ratios are arranged in Table 4. Significant differences between the two species were demonstrated in some ratios (Table 4).

The frontal sinus could be observed in serial sagittal CT sections of the skull (Fig. 7). The lateral and the medial parts of the sinus were located between the outer and the inner tables of the frontal bone, and were not largely developed but compressed in the dorso-ventral direction. The narrow frontal sinus fitted to external shape of the undeveloped frontal bone. The osseous septa divided the frontal sinus into some small compartments (Fig. 7A). The frontal sinus occupied the inner space of the supraorbital process in the most lateral part (Fig. 7D). The 3D CT reconstruction data is seen in Fig. 8. We could obviously see the well-developed cribriform plate in a caudal part of the ethmoid bone. The nasal septum and concha were destroyed in large area of nasal cavity.

\section{DISCUSSION}

The determination of sex has been discussed and realized in the skull and skeleton of the dog $[4,15,19]$. However, it was impossible to evaluate the sex of M1185 and M26696, because the sexual dimorphism remains unclear in the Japanese wolf. As M 100 is a male specimen, we selected the male skulls of the Akita-Inu collections.

Specimens of the Japanese wolf and Akita-Inu are too rare to destroy for age determination applying the histological method of teeth [8-10,22]. Although it is not clear if growth curve reach a plateau, we used specimens with all permanent tooth. These could be considered as an adult or subadult skulls $[3,5]$. Some reports indicated that many skulls of the Japanese wolf from Tanzawa district vary from 206.4 to $226.0 \mathrm{~mm}$ in the total length [11, 14, 17]. We suggest that M 26696 skull may be one of the smallest specimens in adult or subadult animals from Kanto area.

We also dealt with the $\mathrm{LCP} / \mathrm{BL}$ as the mandibular size factor, because LCP/PL could be calculated in only one specimen, M100. So, the LCP/PL offered a significant difference, although the LCP/BL did not show it. As sample size become larger in the future, we suggest that the significant difference may not be confirmed in the length from condyle process.

The LLM/TL did not show the significant difference between species. It has been pointed out that this ratio and the value of LLM are most larger in the Japanese wolf than in Akita-Inu and these are considerable character in the Japanese wolf [11, 13, 14]. Naora [14] and Miyamoto [11, 12] indicated that LLM/TL varies from 11.5 to 12.1 in Japanese wolf and suggested that this animal may possess the relatively largest $\mathbf{M}_{1}$ than any other species of Canis. However, it was denied among specimens used in this study, and this result was also consistent with that in LLM/LCP. While, it is suggested that the size variation may be shown between different archeological periods in the Japanese wolf [14].

The shape data of frontal bone were consistent with those of the former studies [7, 17, 18, 24]. This nonmetrical 

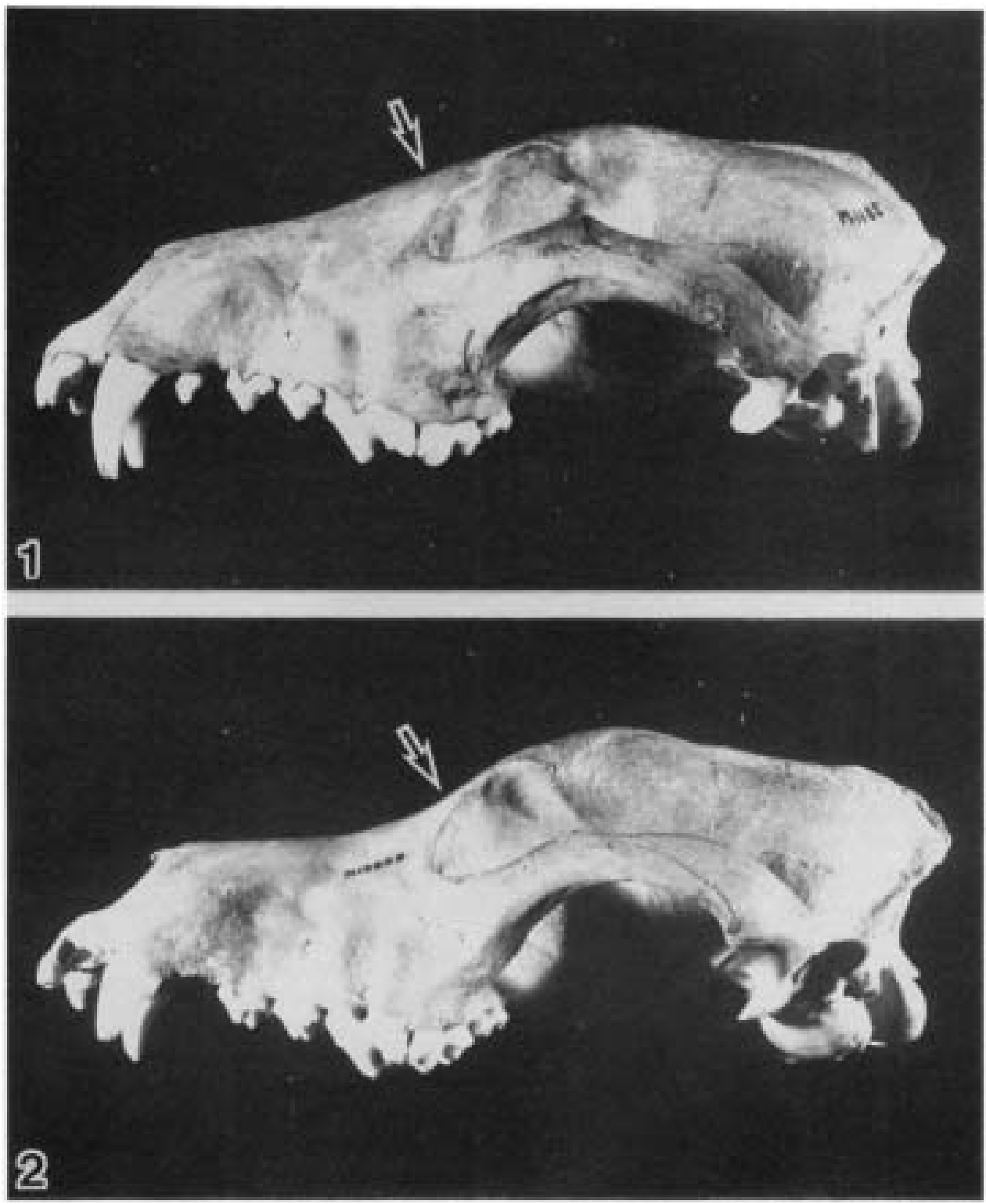

Fig. 1. Lateral aspect of the Japanese wolf skull (M1185). A gentle curve line is observed in the frontal part (arrow).

Fig. 2. Lateral aspect of the Akita-Inu skull (M12920). The dorsal outline rises as a stop in the frontal bone part (arrow).

character has been used as a species identification key [7, 18]. It could be numerized in the interspecies differences of LBS/TL and LBO/TL in this study. We demonstrated that frontal sinus may not be largely developed in the dorsoventral direction in parasagittal area in comparison with the internal shape data of dog skull $[5,25,26]$. Sagittal CT sections could not clarify the structure of the ectoturbinates. However, they may be compressed in shape in accordance with the small frontal sinus. In the ventral region of narrower frontal sinus, complicated structure of the cribriform plate were obviously shown in three dimensional
CT reconstruction data. We suggest that the smaller frontal sinus may have an influence on the respiratory function in this animal. The olfactory sense should be discussed in the Japanese wolf from detailed CT data of nasal area in the future.

ACKNOWLEDGMENTS. We wish to thank Drs. Mitsuru Aimi (Primate Research Institute, Kyoto University (Inuyama, Japan)), Mizuko Yoshiyuki (Faculty of Agriculture, Tokyo University of Agriculture (Tokyo, Japan)), and Masaaki Yoneda (The Japan Wildlife Research 

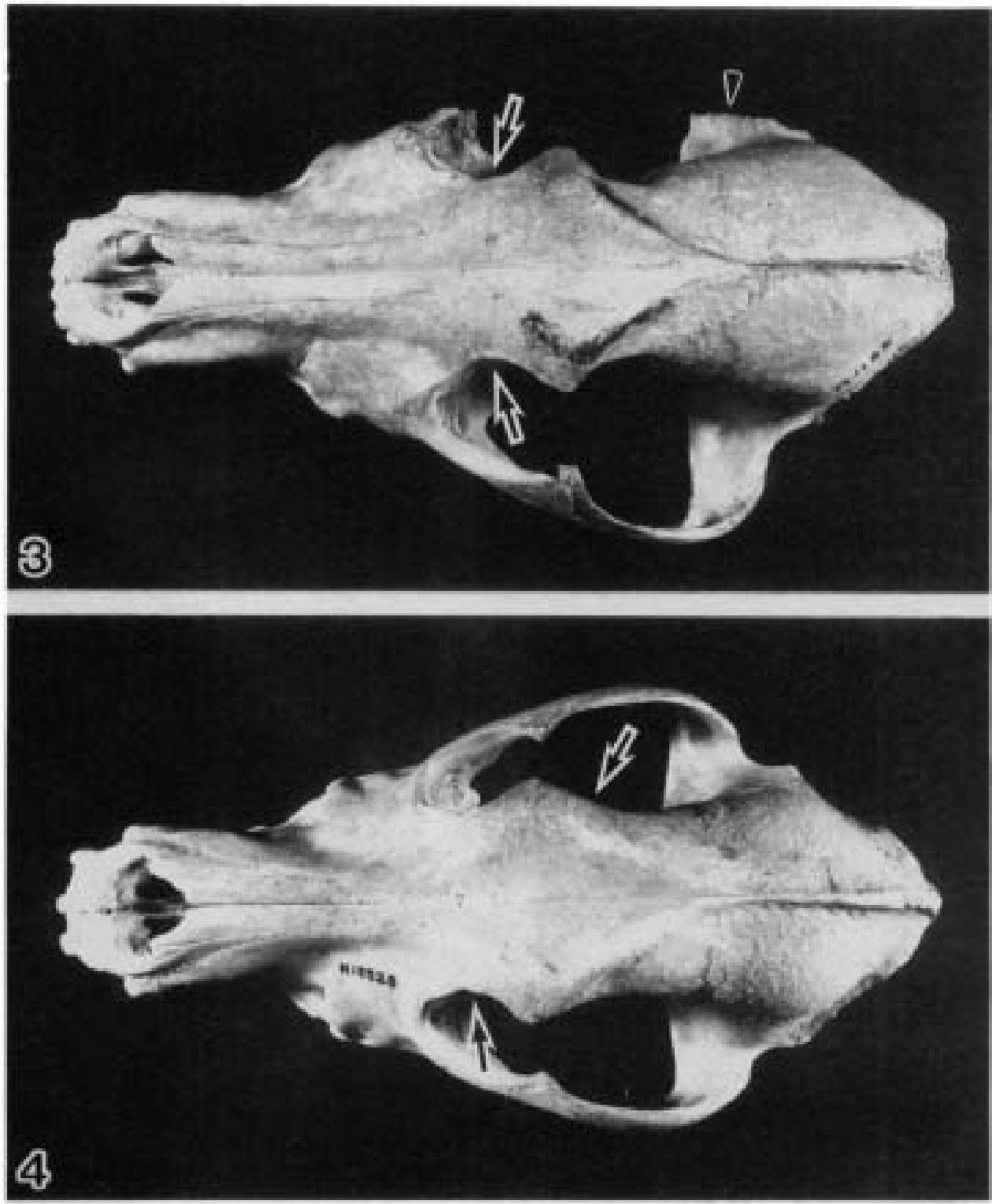

Fig. 3. Dorsal aspect of the Japanese wolf skull (M1185). The frontal bone is not developed in lateral direction and a medial line of orbit deeply curves (arrows). Right zygomatic arch has been broken (arrowhead).

Fig. 4. Dorsal aspect of the Akita-Inu skull (M12920). The frontal bone is well developed laterally (arrows).

Center (Tokyo, Japan)), and Miss Tomoko Ogoh (Department of Zoology, National Science Museum) for their support and encouragement throughout this work.

\section{REFERENCES}

1. Abe, Y. 1936. On the Corean wolf again (an answer to Mr. Pocock). Zool. Mag. 48: 639-644 (in Japanese with English abstract).

2. Driesch, A. 1976. A Guide to the Measurement of Animal Bones from Archaeological Sites. Harvard Univ., Cambridge.
3. Ellenport, C. R. and St. Clair, L. E. 1975. Carnivore Digestive system. pp. 1538-1558. In: Sisson and Grossman's The Anatomy of the Domestic Animals, vol. 2, 5th ed. (Getty, R. ed.), W. B. Saunders, Philadelphia.

4. Ehara, A., Matsumoto, S., and Kinoshita, M. 1986. Skeletal remains of dog from the Asahi-nishi-site, Aichi, 1984. J. Anthrop. Soc. Nippon 94: 307-313 (in Japanese with English abstract).

5. Evans, H. E. 1993. Miller's Anatomy of the Dog, 3rd ed., W. B. Saunders, Philadelphia.

6. Imaizumi, Y. 1970. Systematic status of the extinct Japanese wolf, Canis hodophilax. 1. Identification of specimens. $J$. 

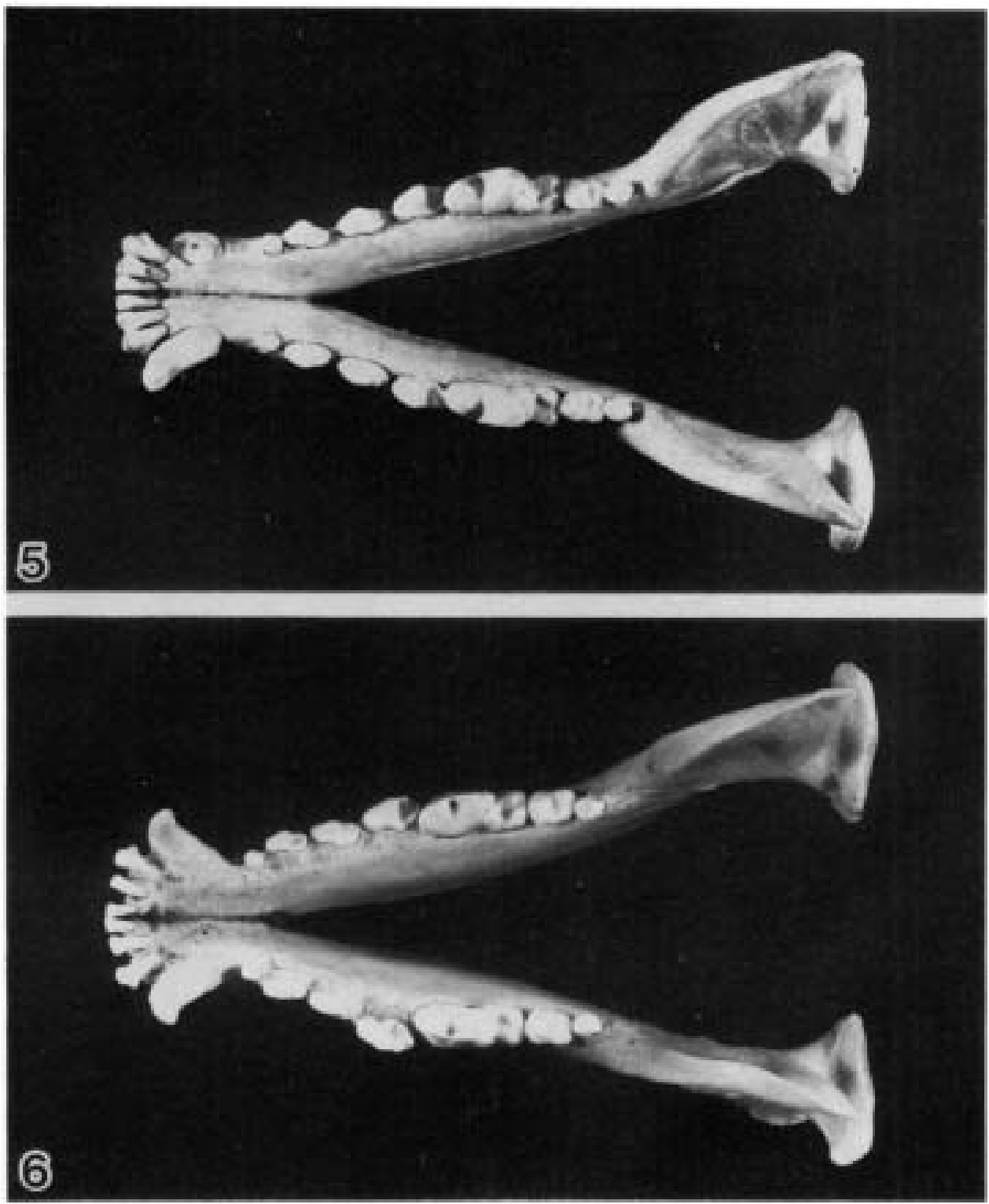

Fig. 5. Dorsal aspect of the Japanese wolf mandible (M1185).

Fig. 6. Dorsal aspect of the Akita-Inu mandible (M12920).

Mamm. Soc. Japan 5: 27-32 (in Japanese with English abstract).

7. Imaizumi, Y. 1970. Systematic status of the extinct Japanese wolf, Canis hodophilax. 2. Similarity relationship of hodophilax among species of the genus Canis. J. Mamm. Soc. Japan 5: 62-66 (in Japanese with English abstract).

8. Laws, R. M. 1962. Age determination of Pinnipedia with special reference to growth layers in the teeth. $Z$. Säugetierkunde 27: 129-146.

9. Linhart, S. B. and Knowlton, F. F. 1967. Determining age of coyotes by tooth cementum layers. J. Wildl. Manage. 31: 362-365.

10. Marks, S. A. and Erickson A. W. 1966. Age determination in the black bear. J. Wildl. Manage. 30: 389-410.

11. Miyamoto, F. and Maki, I. 1983. On the repaired specimen of
Japanese wolf (Canis lupus hodophilax TEMmincK) and its skull newly taken out. Bull. Faculty Education, Wakayama Univ. Natural Science 32: 9-16 (in Japanese with English abstract).

12. Miyamoto, F. 1991. On the skull of Japanese wolf (Canis hodophilax TемміNск) taken out from the mounted specimen preserved in Wakayama Univeristy. Bull. Faculty Education, Wakayama Univ. Natural Science 39: 55-60 (in Japanese with English abstract).

13. Miyao, T., Nishizawa, T., Hanamura, H., and Koyasu, K. 1984. Mammalian remains of the earliest Jomon Period at the rockshelter site of Tochibara, Nagano Pref., Japan. J. Growth 23: 40-56 (in Japanese with English abstract).

14. Naora, N. 1965. On Wolves in Japan. Azekura, Tokyo (in Japanese). 
Table 3. The measurement values $(\mathrm{mm})$ of cranium and mandible

\begin{tabular}{|c|c|c|c|c|c|c|c|c|}
\hline & \multicolumn{3}{|c|}{ Japanese wolf } & \multicolumn{5}{|c|}{ Akita-Inu } \\
\hline & M100 & M1185 & M26696 & M3879 & M12921 & M18303 & M12920 & M19301 \\
\hline $\mathrm{TL}$ & 216.3 & 1 & 203.3 & 225.2 & 223.7 & 214.6 & 216.5 & 203.4 \\
\hline BL & 191.2 & 184.9 & I & 196.5 & 201.0 & 194.1 & 194.1 & 183.6 \\
\hline CBL & 201.8 & 197.4 & I & 207.4 & 212.1 & 207.6 & 207.0 & 195.7 \\
\hline UNL & 114.0 & 1 & 110.6 & 126.4 & 117.1 & 111.9 & 118.4 & 107.8 \\
\hline PL & 103.0 & 98.9 & 98.1 & 111.6 & 108.1 & 109.0 & 111.8 & 102.7 \\
\hline FL & 105.8 & 102.8 & 98.8 & 106.4 & 113.7 & 106.1 & 105.6 & 99.2 \\
\hline DON & 93.2 & 95.8 & 88.3 & 94.5 & 93.8 & 91.0 & 96.9 & 90.9 \\
\hline $\mathrm{ZB}$ & 123.7 & l & 116.9 & 133.4 & 125.4 & 121.4 & 113.2 & 116.7 \\
\hline GNB & 58.3 & 60.5 & 50.4 & 59.0 & 57.2 & 58.2 & 56.4 & 56.4 \\
\hline GMB & 74.8 & 71.8 & 66.1 & 84.6 & 79.6 & 72.3 & 72.7 & 74.9 \\
\hline FB & 58.5 & 59.0 & 57.4 & 61.1 & 62.6 & 55.4 & 56.8 & 50.3 \\
\hline LBS & 32.7 & 35.9 & 33.6 & 42.5 & 37.4 & 42.8 & 43.3 & 34.5 \\
\hline LBO & 34.8 & 38.0 & 34.0 & 43.1 & 41.6 & 37.4 & 41.0 & 32.5 \\
\hline GPB & 67.6 & 68.0 & 63.4 & 77.4 & 73.6 & 71.4 & 73.4 & 65.8 \\
\hline HOT & 71.1 & l & 68.1 & 78.0 & 79.8 & 75.9 & 70.9 & 68.7 \\
\hline LCP & 155.2 & 157.6 & I & 168.1 & 167.0 & 166.9 & l & 155.6 \\
\hline LAA & 140.8 & l & 130.5 & 140.9 & 143.5 & 141.9 & I & 133.5 \\
\hline HVR & 67.5 & 65.3 & 61.1 & 73.8 & 68.8 & 64.3 & I & 62.3 \\
\hline LIM & 101.0 & 101.4 & 96.8 & 102.6 & 102.8 & 105.5 & 107.2 & 98.1 \\
\hline LCR & 85.2 & 87.9 & I & 87.0 & 83.9 & 90.3 & 89.5 & 83.2 \\
\hline LUC & 11.2 & 12.0 & I & 12.7 & 12.7 & 13.0 & 12.5 & 11.8 \\
\hline BUC & 8.0 & 7.5 & l & 8.6 & 7.6 & 8.3 & 7.8 & 7.1 \\
\hline LLC & 11.7 & 12.0 & I & 12.8 & 12.4 & 12.4 & I & 12.4 \\
\hline BLC & 8.3 & 8.1 & / & 9.4 & 9.1 & 10.0 & l & 8.6 \\
\hline LP4 & 20.5 & 20.5 & 18.6 & 20.0 & 19.8 & 21.8 & 19.0 & 20.1 \\
\hline BP4 & 11.2 & 9.9 & 8.8 & 11.8 & 12.5 & 12.8 & 11.9 & 11.1 \\
\hline LUM & 14.3 & 14.0 & 13.2 & 12.0 & 13.3 & 14.2 & 14.9 & 13.3 \\
\hline LLM & 24.0 & 24.8 & 22.5 & 24.7 & 25.2 & 26.2 & l & 23.4 \\
\hline
\end{tabular}

/: The items could not be measured, because specimens are partially broken or do not include the mandible (M12920).

Table 4. Measurement ratios (\%) of cranium and mandible and their significant differences between the two species

\begin{tabular}{|c|c|c|c|c|c|c|c|c|}
\hline & \multicolumn{3}{|c|}{ Japanese wolf } & \multicolumn{5}{|c|}{ Akita-Inu } \\
\hline & M100 & M1185 & M26696 & M3879 & M12921 & M18303 & M12920 & M19301 \\
\hline UNL/TL & 52.7 & l & 54.4 & 56.1 & 52.3 & 52.1 & 54.7 & 53.0 \\
\hline $\mathrm{PL} / \mathrm{TL}^{\mathrm{c})}$ & 47.7 & l & 48.3 & 49.6 & 48.3 & 50.8 & 51.6 & 50.5 \\
\hline FL/TL & 48.9 & l & 48.6 & 47.2 & 50.8 & 49.4 & 48.8 & 48.8 \\
\hline DON/TL & 43.1 & l & 43.4 & 42.0 & 41.9 & 42.4 & 44.8 & 44.7 \\
\hline $\mathrm{ZB} / \mathrm{TL}$ & 57.1 & l & 57.5 & 59.2 & 56.1 & 56.6 & 52.3 & 57.4 \\
\hline GNB/TL & 27.0 & I & 24.8 & 26.2 & 25.6 & 27.1 & 26.1 & 27.7 \\
\hline GMB/TL & 34.6 & l & 32.5 & 37.6 & 35.6 & 33.7 & 33.9 & 32.4 \\
\hline $\mathrm{FB} / \mathrm{TL}$ & 27.0 & l & 28.2 & 27.1 & 28.0 & 25.8 & 26.2 & 24.7 \\
\hline $\mathrm{LBS} / \mathrm{TL}^{\mathrm{b}}$ ) & 15.1 & l & 16.5 & 18.8 & 16.7 & 19.5 & 20.0 & 17.0 \\
\hline $\mathrm{LBO} / \mathrm{Tl}^{\mathrm{a})}$ & 16.1 & l & 16.7 & 19.1 & 18.6 & 17.4 & 18.9 & 16.0 \\
\hline GPB/TL $\left.{ }^{d}\right)$ & 31.3 & l & 31.2 & 34.4 & 32.9 & 33.3 & 33.9 & 32.4 \\
\hline HOT/TL & 32.9 & I & 33.5 & 34.6 & 35.7 & 35.4 & 32.7 & 33.8 \\
\hline $\mathrm{LCP} / \mathrm{TL}^{\mathrm{c})}$ & 71.8 & I & l & 74.6 & 74.7 & 77.8 & / & 76.5 \\
\hline LLM/TL & 11.1 & I & 11.1 & 11.0 & 11.3 & 11.3 & / & 11.5 \\
\hline LLM/LCP & 15.5 & 15.7 & l & 14.7 & 15.1 & 15.7 & l & 15.0 \\
\hline $\mathrm{LCP} / \mathrm{BL}$ & 81.2 & 85.2 & l & 88.0 & 83.1 & 86.0 & l & 84.7 \\
\hline UNL/GNB* & 51.3 & l & 45.5 & 46.7 & 48.8 & 52.0 & 47.6 & 52.3 \\
\hline
\end{tabular}

/: The ratios could not be obtained. The values with footnote showed a significant difference between the two species. a) $\mathrm{P}<0.1$, b) $\mathrm{P}<0.05$, c) $\mathrm{P}<0.02$, d) $\mathrm{P}<0.01$. * Neurocranium index. 

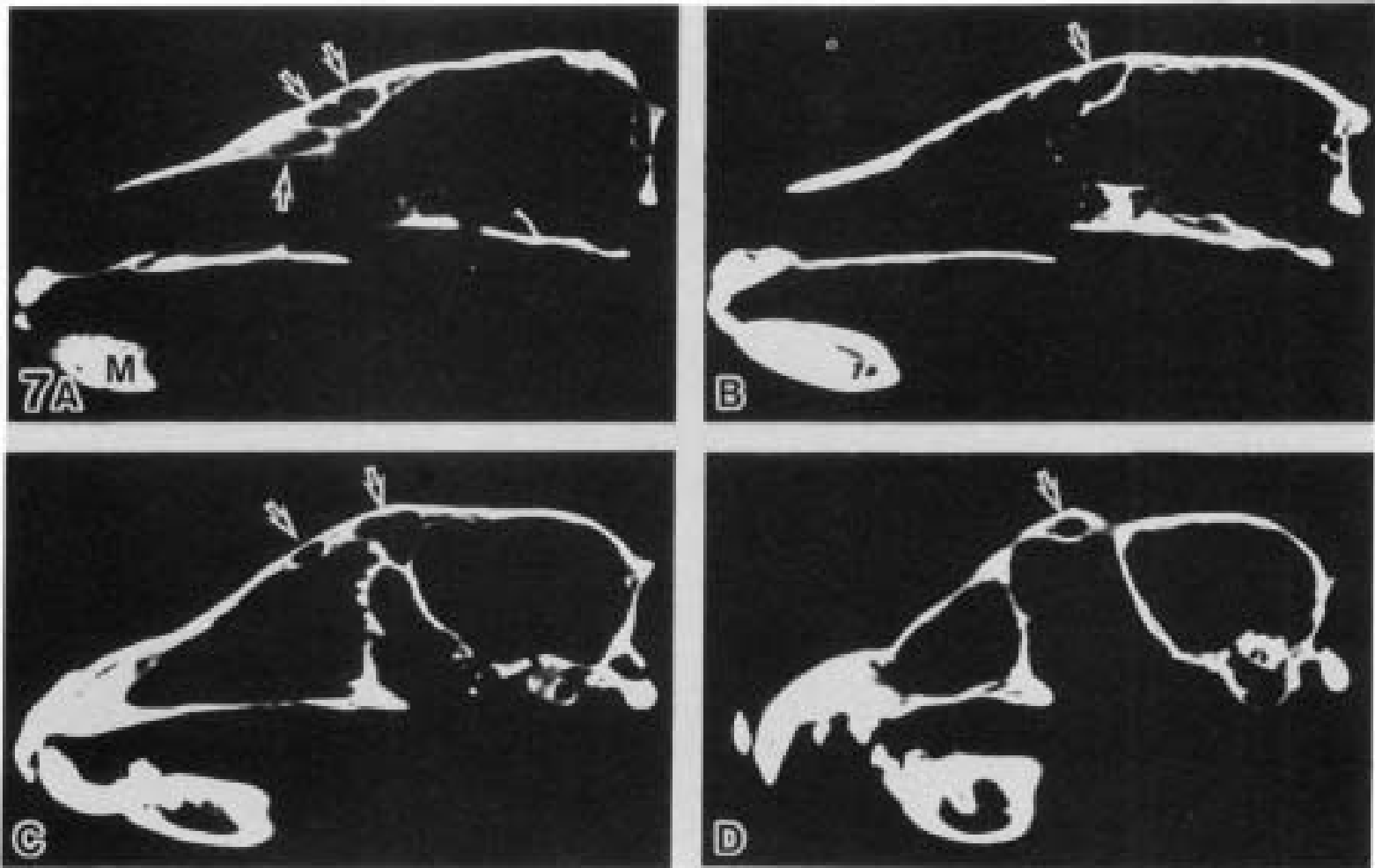

Fig. 7. CT serial sagittal sections of the Japanese wolf skull (M1185). The lateral and the medial parts of the sinus are located between the outer and the inner tables of the frontal bone, and are not be largely developed and compressed in the dorso-ventral direction. A: Median plane. The osseous septa divide the frontal sinus into some small compartments (arrows). M: mandible. B: Parasagittal section of $6 \mathrm{~mm}$ from median plane. Arrow: frontal sinus. C: $12 \mathrm{~mm}$ from median plane. Arrows: frontal sinus. D: $18 \mathrm{~mm}$ from median plane. The frontal sinus occupies the inner space of the supraorbital process in the most lateral part (arrow).

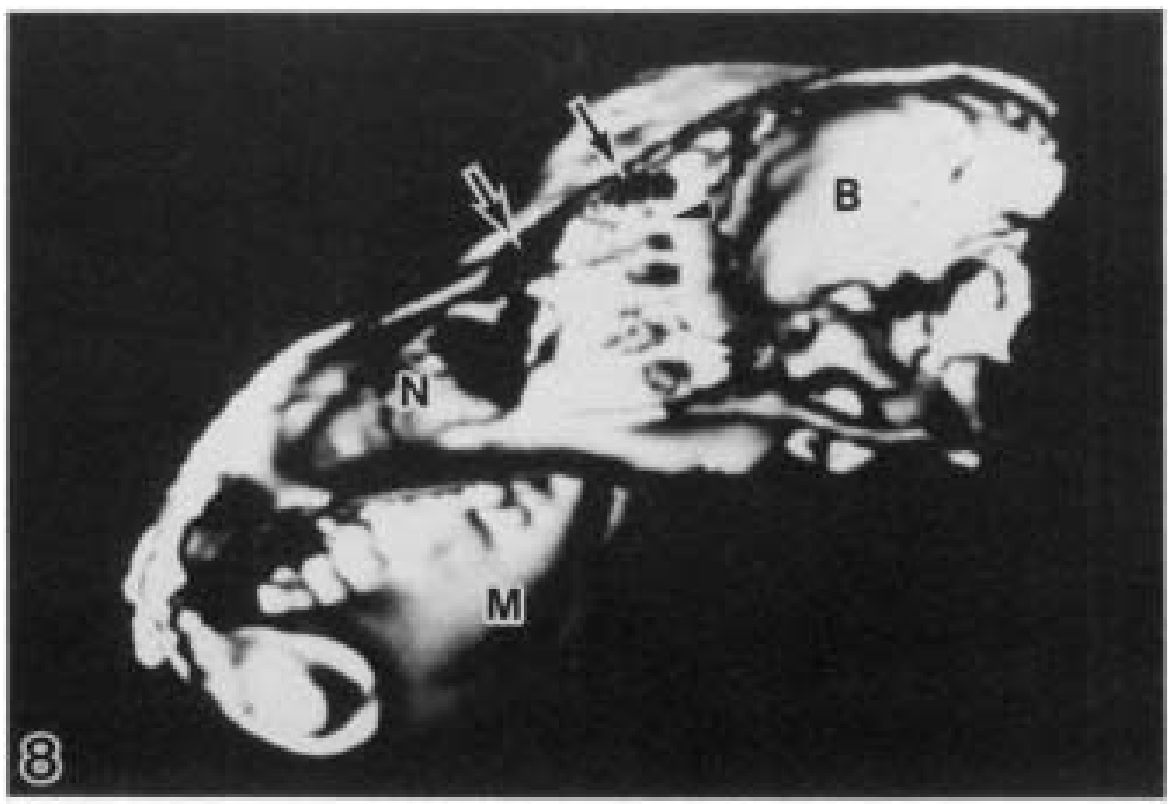

Fig. 8. The section of 3D CT reconstruction image in left parasagittal area (M1185). The frontal sinus is not be largely developed but compressed in the dorso-ventral direction (arrows). The well-developed cribriform plate is seen in a caudal part of the ethmoid bone (arrowhead). The nasal septum and concha are destroyed in large area of nasal cavity $(\mathrm{N})$. B: braincase, $\mathrm{M}$ : mandible. 
15. Obara, I. and Imaizumi, Y. 1980. Cranial and dental characters of the Japanese native dogs. Rep. Soc. Res. Native Livestock 9: 139-157 (in Japanese with English abstract).

16. Obara, I. 1990. A fore paw of Japanese wolf, Canis hodophilax, preserved in Kiyokawa-mura, Kanagawa Prefecture. Natl. His. Rep. Kanagawa 11: 67-69 (in Japanese).

17. Obara, I. 1990. Skulls of Japanese wolf, Canis hodophilax, preserved as old private houses in Atsugi-shi and Kiyokawamura, Kanagawa Prefecture. Natl. His. Rep. Kanagawa 11: 53-65 (in Japanese).

18. Obara, I. and Nakamura, K. 1992. Notes on a skull of socalled Yama-Inu or wild canine preserved in the Minamiashigara Municipal Folklore Museum. Bull. Kanagawa Prefect. Mus. 21: 105-110 (in Japanese with English abstract).

19. Onodera, S., Shigehara, N., and Eto, M. 1987. Discriminant analysis of the sexual differences of the skeletons in Shiba dogs (Canis familialis). Acta Anat. Nippon. 62: 19-32 (in Japanese with English abstract).

20. Pocock, R. I. 1935. The races of Canis lupus. Proc. Zool.
Soc. London 105: 647-686.

21. Saito, H. 1963. Osteometrie der Caniden. Author's publication. Kokusai-Bunken, Tokyo.

22. Scheffer, V. 1950. Growth layers on the teeth of Pinnipedia as an indication of age. Science 112: 309-311.

23. Suématu, S. 1950. On the third stuffed specimen of Canis lupus japonicus, a scientifically valuable specimen. Gakugei Kenkyu, Studies in Natural Science 1: 85-88 (in Japanese with English abstract).

24. Tasumi, M. 1991. Reality of the Japanese wolf as investigated from the skull remains. The Bone 6: 119-128 (in Japanese)

25. Tateno, Y. and Yamada, K. 1993. The Atlas of MRI and CT in Cats and Dogs. Univeristy of Tokyo Press, Tokyo (in Japanese).

26. Tsukise, A., Tanaka, S., Urahashi, S., and Nakazawa, M. 1993. Atlas of Imaging Anatomy of the Dog. Chikusan Publishing, Tokyo (in Japanese). 